\title{
THE DETERMINATION OF THE AVAILABLE EXTRACT OF MALT.
}

\author{
By Lawrence Briant.
}

(Read at the Meeting, November 7, 1900.)

THe determination of the available extract of malt is one in which there is room for considerable divergence of result. The operation is a very different one to the estimation of an acid or a base, for it is an endeavour in the laboratory to ascertain the amount of extract which is obtainable by a brewer in his actual brewing operations, the amount being dependent upon the specific gravity and quantity of saccharine wort obtainable from a known quantity of malt during the mashing and sparging operation in the brewery. My object in bringing this matter before you to-night is to point out the discrepancies which at present exist between determinations by different methods, and to suggest a method which is at once easy of performance and gives accurate results. Under the present condition of things, it is not an uncommon thing to find a difference of 2,3 , or even 5 , pounds per quarter in the results given in different analyses. Such a difference would be a very serious matter to the brewer. Taking, for instance, a variation of 5 pounds per quarter (and this I have actually known to occur), and assuming that the brewer mashed 50 quarters of the malt per day, the difference in yield of beer per week of five days' working, represented by the divergence in the analysts' results, is no less than $62 \frac{1}{2}$ borrels of a $20 \mathrm{lb}$. beer. It is natural that brewers may think these discrepancies are proof of very careless work, yet the fact is that they are really due to the varying methods adopted in laboratories.

In attempting to estimate the extract yielded by a malt, the obvious method seems to be to imitate as closely as practicable the actual operations as carried out in a brewery. The brewer mixes his ground malt with water in about the proportion of 2 barrels of water to 1 quarter of malt-that is, 720 parts of water to 336 parts of malt. He allows this mixture to stand at a temperature depending upon the character of the malt and the class of beer which he is producing, but which lies between 145 and 155. At the expiration of a given time-generally two hours-saccharification being complete-he draws off the extract and washes out that which remains in the "goods." But this "sparging" operation does not merely consist of washing. The brewer sparges with water at a temperature considerably more elevated than that of his mash. As a consequence, the heat of the mash slowly rises, and starch, which during the malting operation has been imperfectly modified, gradually comes into solution, and the amount so dissolved will depend upon the original character of the malt, upon the temperature of the sparging water and the amount of the sparge. We have therefore a varying set of conditions which it is not easy to precisely imitate in the laboratory, and the extract yielded by a malt will depend a great deal upon these factors. The following results show this to be the case as regards temperature of stand of mash : 


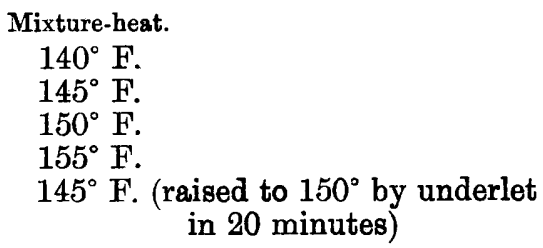

Extract per 336 pounds. $90 \cdot 3$ pounds $91 \cdot 2$, $90 \cdot 1$, 88.9 ," $92 \cdot 3 \quad$,

The extract will also, as above mentioned, vary with the temperature of sparging water. This is shown by the following figures:

\begin{tabular}{|c|c|c|}
\hline $\begin{array}{l}\text { Mixture-heat. } \\
149^{\circ} \mathrm{F} \text {. }\end{array}$ & $\begin{array}{c}\text { Sparge-heat. } \\
160^{\circ} \mathrm{F} .\end{array}$ & $\begin{array}{c}\text { Extract per } 336 \text { pounds. } \\
91.3 \text { pounds. }\end{array}$ \\
\hline $149^{\circ} \mathrm{F}$ & $\left(\begin{array}{l}175^{\circ} \mathrm{F} . \\
\left.185^{\circ} \mathrm{F} .\right)\end{array}\right.$ & $93 \cdot 4 \quad "$ \\
\hline $149^{\circ} \mathrm{F}$ & 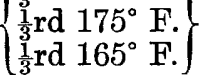 & $95 \cdot 7$ \\
\hline
\end{tabular}

So that we see, by different temperatures of sparge, the extract may be affected to the extent of $4 \frac{1}{2}$ pounds per quarter.

Yet another condition influences the result, namely, the fineness of grinding. There is, unfortunately, no standard of grinding adopted by chemists, yet the degree of fineness much influences the result. This is seen in the following figures:

\begin{tabular}{|c|c|c|c|c|c|c|}
\hline \multirow{2}{*}{\multicolumn{2}{|c|}{ Very coarse grinding }} & \multirow{2}{*}{\multicolumn{5}{|c|}{ Extract per 336 pounds }} \\
\hline & & & & & & \\
\hline Coarse & ," & $\cdots$ & $\cdots$ & $\ldots$ & $94 \cdot 4$ & ", \\
\hline Fine & ", & $\ldots$ & $\ldots$ & $\cdots$ & $95 \cdot 7$ & ", \\
\hline Crushed & ctar & $\ldots$ & $\ldots$ & $\ldots$ & $94 \cdot 7$ & \\
\hline
\end{tabular}

It is quite evident that, as precise temperature of mixture heat-sparge heat and grinding all exert a considerabls influence upon the extract-it is very difficult to get regularity of working upon these lines.

For many years the author was in the habit of determining the extract of malt in a miniature mash conducted on precisely the lines obtaining in breweries, though the influence of bulk was of course absent ; but it was found that very slight alterations in temperature, in dilution of mash, in heat, and in amount of sparging water, considerably affected the results, so that it was necessary to take the average of several determinations; it was not always possible to know at what temperature the malt would be mashed or sparged. Owing to these difficulties, he has now discarded this method as more troublesome and less reliable than that which will be presently described.

A method which is very largely adopted is that of Heron, as described in a paper read before the Society of Chemical Industry (Society of Chemical Industry, 1888, vol. vii., p. 259), and afterwards modified in a paper read before the Institutes of Brewing, in 1895 (Journal of the Federated Institutes of Brewing, vol. i., p. 116). This method consists in weighing out 50 grammes of ground malt, transferring to a flask, and adding 400 c.c. of water at such a temperature that the initial mixture heat may be $122^{\circ} \mathrm{F}$. The whole is immersed in a water-bath and the temperature gradually raised, so that at the end of an hour it has reached $158^{\circ}$. The mash is now 
raised to $190^{\circ}$ for fifteen minutes, then cooled to $60^{\circ}$, and the whole made up to the bulk of 515 c.c. After being shaken, the liquid is filtered off, its specific gravity determined, and the extract calculated in the ordinary way, the assumption being made that the liquid occupies a bulk of precisely 500 c.c. There are several advantages in this method. The process is simple and rapid, no sparging is required; thus, errors due to that source are eliminated, whilst differences in mixture heat have very little influence upon the extract yielded, as is shown by the following figures:

\section{Heron's Method.}

$\begin{array}{cc}\text { Mixture-heat. } & \text { Extraet per } 336 \text { pounds. } \\ 140^{\circ} \mathrm{F} . & 95 \cdot 2 \\ 150^{\circ} \mathrm{F} . & 95 \\ 160^{\circ} \mathrm{F} . & 95\end{array}$

It is a remarkable fact that whilst with thick mashes temperature exerts a very important influence on yield, with thin mashes practically no difference occurs.

But this method is not, in my opinion, entirely satisfactory. Heron, it will be remembered, makes up to a constant bulk of 515 c.c., yet there is a very great variation in the amount of husk contained in malt samples. This is abundantly evident to anyone who is accustomed to the analysis of malts, and the amount of husk present in a thin barley foreign malt is manifestly very much larger than that in a thin-skinned, plump, bold, English or Scotch barley malt. There is thus an error introduced due to this difference for which Heron has not made allowance. Further than this, the raising of the mash to $190^{\circ}$ for fifteen minutes is open to the objection that, in practice, the mash never rises to such a temperature, very seldom (even during sparging) exceeding $160^{\circ}$.

Stern (Journal of the Federated Institutes of Brewing, vol. i., p. 448) proposes to overcome this source of error by making two mashes, both of which are mashed under Heron's conditions, but to one a known bulk of water is afterwards added. The specific gravity of the two filtrates is ascertained, and from that, by means of algebraic formula, it is possible to calculate the true extract. To those of us, however, who have in the course of a season to analyse a very large number of samples of malt, Stern's method is manifestly too laborious for practical application. The method which I propose eliminates the error arising from difference in amount of husk, and gives the true extract value of the malt sample. I proceed as follows :

Weigh out roughly a little over 50 grammes of the malt, and grind. Place the whole of the ground malt in a tared scoop, and accurately weigh 50 grammes. Now place the ground malt in an ungraduated ordinary boiling-flask of about 550 c.c. capacity, and run in as rapidly as possible a bulk of water at a temperature of $160^{\circ} \mathrm{F}$., which shall be equal in volume to 400 c.c. if measured at $60^{\circ} \mathrm{F}$. The measurement of this bulk of water is made in a flask or other suitable apparatus, graduated at the point occupied at $160^{\circ}$ by 400 c.c. of water at $60^{\circ}$. Immediately thoroughly mix the contents of the flask. Loosely cork the flask to prevent evaporation, place in a waterbath maintained at a temperature of $150^{\circ}$, and allow to stand for two hours.*

* One hour's stand is usually sufficient, but for some malts a longer stand is necessary, and two hours' digestion insures complete extraction of all classes of malt. 
At the end of this time cool the mash to $60^{\circ} \mathrm{F}$., add 100 c.c. of water at $60^{\circ}$, mix thoroughly, filter bright, and take the specific gravity of the wort. We are now dealing with an actual bulk of 500 c.c. of liquid plus the volume occupied by the saccharine matter dissolved from the malt. It is necessary for us to ascertain what this volume is, and this we can celculate from the specific gravity of the liquid. To take an example: Suppose its specific gravity to have been 1028, now divide the excess weight over 1000 by the solution factor $3 \cdot 86,=7 \cdot 25$, the solid matter present in 100 c.c. of the wort. This multiplied by $5(7 \cdot 25 \times 5=36.25)$ gives us the amount of solid matter $(36.25)$ dissolved from the malt. Now, as 15.9 parts of saccharine matter occupy a bulk when dissolved of 10 parts, it will be seen that the bulk occupied by the saccharine matter dissolved from the 50 grammes of malt is $15 \cdot 9: 36 \cdot 25:: 10=23$ c.c.

Our total dilution of mash is therefore 523 c.c., and this corresponds with the rate of 9.75 barrels per quarter. In order to further simplify the calculation, we may multiply our excess weight over 1000 of specific gravity direct by the factor 3.51 , which gives the true extract per quarter of 336 pounds. Thus, $28 \times 3.51=98 \cdot 2$ pounds per quarter of 336 pounds. In practice this factor may always be used. The variations in specific gravity which occur are not sufficient to materially affect the result.

The modified process, therefore, which I suggest, consists in mashing 50 grammes of malt with 400 c.c. of water at a mixture-heat of $150^{\circ} \mathrm{F}$., standing for two hours, cooling to $60^{\circ}$, adding 100 c.c. of water, mixing, filtering, taking the specific gravity, and multiplying excess weight over 1000 by the factor $3 \cdot 51$.

\section{Discussion.}

Dr. Srkes said he perfectly agreed with Mr. Briant as to the necessity that some definite scheme for analysing malt should be agreed on. The process Mr. Briant had suggested seemed to him to be a very ingenious one, and likely to surmount many difficulties.

Mr. Arthur R. Ling said he thought most of those who had to make determinations of extract in brewery malts had found the method proposed by Mr. Briant in his well-known text-book too lengthy, although it undoubtedly gave results more in harmony with those obtained in actual practice than did the shorter methods. $\mathrm{He}$ had been in the habit of using the method devised by Mr. Heron, but, like Mr. Briant, he had had doubts whether the volume occupied by the grains from 50 grammes of the malt was always exactly 15 c.c., as it had been assumed to be by Mr. Heron. Recently, therefore, he had carried out the determination in a manner which did not necessitate such an assumption. Fifty grammes of the ground malt were added to 400 grammes of water, at the requisite temperature, contained in a tared beaker or flask. The mashing was conducted as usual, but, instead of ultimately making up the cooled mash to 515 c.c. with water, the beaker or flask was placed on a balance, and sufficient water weighed in that the total quantity (including that already present) amounted to exactly 500 grammes; the specific gravity of the filtrate was then determined as usual. It was only right to add that, as far as his experience 
went, the results agreed with those obtained when working in accordance with Mr. Heron's directions.

Mr. JuLIAN L. BAKER said that, as laboratory results were never absolutely representative of what took place in the mash-tun, it would be highly desirable that all brewing chemists should use one method for the determination of extract; and he personally preferred Heron's widely-used method on account of the very important desideratum-rapidity.

Mr. Chapman said that the failure to make a determination of the available extract of a given sample of malt, or the incorrect determination of such extract, might result, as Mr. Briant had shown, in a considerable loss to the brewer, owing to the fact that unconsciously he might be obtaining from his malt a much smaller proportion of soluble matter than it ought to yield. If the malt contained soluble substances only, which had simply to be extracted, the matter would be a very simple one; but the determination had to be based on the amount of soluble matter formed as the result of a series of chemical changes, influenced by a number of conditions, and an approximation ultimately arrived at which should as nearly as possible represent the truth. From his own experience, he was of opinion that there could be no such thing as "the brewery extract" of a sample of malt; and that fact-at any rate, it appeared to him to be a fact-had led him to adopt a process yielding numbers which were always in excess of those obtained in the brewery, but which bore to the brewery extract a definite and (by him) understood relationship. Given one and the same malt, two brewers-situated, it might be, in the same street -would obtain two different quantities of extract, both perhaps working correctly, but using different procedure. The extract depended upon the precise character of the starch contained in the malt, or, in other words, the amount of modification which the contents of the grain had undergone, and also upon the procedure in the brewery itself-whether the mash was allowed to stand for a longer or shorter time; whether the mashing temperature was higher or lower; whether or not an underlet was used; whether a strong beer or a weak beer was being brewed, all of which were factors in actual working procedure, which exercised considerable influence upon the extract obtained. The possibility of ever arriving at a correct laboratory estimation of the "brewery extract," except by a compensation of errors or something of that kind, seemed to be precluded by several considerations. For instance, uniformity of grinding, which was referred to by Mr. Briant, was quite impracticable in the case of a heterogeneous material like malt. Moreover, laboratory experiments were necessarily made on a small scale, whereas in the brewery the extracts were determined when all the operations were concluded. The specific gravity was not by any means strictly proportional to the concentration; and a distinct error was introduced in the calculation of the small laboratory numbers to the large numbers of the brewery. Perhaps, therefore, after all, a purely arbitrary method was as likely to give satisfactory results as one in which an endeavour was made to closely imitate actual brewery practice. In addition to the intrinsic interest of Mr. Briant's paper, it was, he felt, of value as a plea for uniformity in various branches of analytical work; and there was no department in which the necessity for such uniformity was more marked than in the analysis of brewing materials. 
Mr. Hehner said that there were many articles besides beer in the case of which the chemist was called upon to make analyses of products which were afterwards used by the manufacturer; and the question arose as to what the manufacturer expected to learn from the analyses. Did he expect to learn how much the manufacturer's yield would be? or the actual quantity of any given constituent present in the article examined? In a gold ore, for example, the manufacturer desired to know how much gold was actually present; whether he got out that amount was another question, and probably in no two cases would the quantity turned out be the same. $\mathrm{He}$ (Mr. Hehner) himself made a great many analyses of crude glycerine, which was afterwards worked up into pure glycerine by distillation. He determined the actual percentage of glycerol present in the samples, not the quantity' a manufacturer would expect to get out, which varied very widely. His function was to educate the manufacturer into a knowledge of what theoretically he might get out, it being the manufacturer's business to work as near to theory as possible. The same was presumably the case with malt. The chemist ought to say how much extract the brewer, with the most careful working, should be able to obtain. The brewer would understand that on a large scale there must be a certain loss, and that he would not quite reach the ideal.

Mr. LING said that if it were possible to estimate the starch in malt with anything like precision, a valuable scientific figure would be the extract calculated from the percentage of starch. The latter was the main extract-yielding constituent of the malt.

Mr. Briant, in reply, said that for many years he had made use of the process described by Mr. Ling. It was very good in its way, but there was still the same error arising from the solution of the sugar, which was not overcome any more than in the ordinary process of $\mathrm{Mr}$. Heron. If merely the theoretical extract was to be given, then, as Mr. Ling had said, the starch could not be made the basis of calculation - at any rate, until a good method was devised for estimating it. If the theoretical extract was to be given, he thought it would be wise to adopt the recommendation of one of the Continental conferences-namely, that the whole of the malt should be ground to an extremely fine powder, and that the water should be at first cold, and gradually raised practically to boiling-point. Then everything extractible would be extracted, and something approaching uniformity might be hoped for between different chemists. But he doubted whether a figure so obtained would be appreciated by the brewer. He agreed to a certain extent with Mr. Hehner; but the brewer desired to get from his chemist some idea of the quantity of extract he was likely to obtain, perhaps by making a certain deduction from the figures of the chemist. Sometimes, for particular classes of beer, the brewer knowingly sacrificed extract, or, in other words, mashed at a temperature at which he knew the maximum extract would not be yielded. It paid him to do so in order to get quality. But he looked to his chemist for an approximate figure; and if a satisfactory figure of that kind was to be obtained, the endeavour should be made to eliminate an error such as occurred in all those processes in which no proper allowance was made for the difference in the quantities of husk in different samples of malt. This difference was considerable, and unless allowance was made for it, undoubtedly an error was introduced in to the 
analyses. No doubt, as Mr. Chapman had said, the absolute amount of extract could not be given which a brewer could obtain; but a comparative figure could be given, and the brewer would in practice be able to decide how nearly that figure approximated to his own result. 